\title{
Bilingual Dictionary Development Mechanism the Area of the Archipelago as A Way of Coaching and Language Retention in the Era Of Globalization
}

\author{
$1^{\text {st }}$ Teguh Yuliandri Putra ${ }^{1}, 2^{\text {nd }}$ Suhartini Sumadi ${ }^{2}$, \\ \{teguhputra559@yahoo.com ${ }^{1}$,suhartini.sumadi@gmail.com² ${ }^{2}$, \\ Universitas Pendidikan Muhammadiyah Sorong, West Papua, Indonesia ${ }^{1,2}$
}

\begin{abstract}
Regional Language Nusantara has lost the "spirit" of love from its speakers in the current era of globalization. In this era, demand for communication was so powerful for policy makers in the field of language to further perfect and improve all sectors related to the problem of language development. The purpose of this study is to describe a mechanism that can be used as a benchmark in the preparation of regional language dictionaries in the archipelago using a study of observing the words (lexicons) in regional vocabulary retention. The method used in this study is the R \& D method, in the process the method is supported by the use of instruments 100-200 basic words of Swadesh to be developed in the form of a dictionary. Nusantara language in this study is focused on several Regional languages in the Eastern Region of Indonesia (Papua).
\end{abstract}

Keywords: Language, Dictionary, Coaching, Defense, Lexicon and Retention.

\section{Introduction}

Language in theory is an arbitrary sound symbol system that is used by members of social groups to cooperate, communicate, and identify themselves (Chaer, 2007: 32). Language has an important role for humans in conveying information both orally and in writing. Submission of this information is carried out in the form of communication and the media used are linguistic / language media.

Language is a linguistic discipline which today has undergone changes because in essence language is dynamic, the change appears at the stages of its development, beginning with the stages of speculation (how to determine conclusions); stages of observation and classification by way of classifying all the facts of language carefully; then, the stages of theoretical formulation. Thus, from that change linguistics has finally been said to be a study of scholarship.

Scientifically, regional languages are one of the languages that can not be separated from the views of linguists, because basically the language of the Region has always been the main tool of communication between people in a region. Indonesia is an archipelago that has a unique or distinctive characteristic of Regional languages from Sabang to Marauke. This distinctive feature reflects the Indonesian nation as a nation that is rich in language culture.

Regional language culture in Indonesia is increasingly day-to-day, continuing to decline in quality. In the current era of globalization, generally young gerasi who are often called the 
generation of the present (today) tend to no longer use the language of the Region and even many do not understand the language of the region anymore. There are many concerns expressed by linguists, teachers, community leaders, even ordinary people who understand this problem. So that in a short period of time, this will be a collective anxiety.

In collective anxiety over the problem of decreasing love and pride in this Regional language, making the development of dictionaries as an effort to protect the language of the Archipelago from the threat of extinction. A simple dictionary according to KBBI can be interpreted as a kind of reference book that explains the meaning of words. It serves to help someone get to know new words. In addition to explaining the meaning of the word, the dictionary may also have a guideline designation, the origin (etymology) of something said and also an example of use for something said. The development of dictionaries in this case can be a support for regional language defense in the era of globalization.

In the 21 st century it is understood as a global era marked by the development of science and technology. The era of the development of science and technology is actually a momentum to further improve the quality of human resources. HR quality is characterized by the development progress in various life features. One of the things that is no less important, is the development in the field of fostering and maintaining Regional languages as a symbol of strength and the high ancestral value of an area. One way is to develop a systematic and efficient dictionary as a forum for fostering and maintaining Regional languages.

From the above conditions, of course there is an interesting phenomenon to find data and find out the latest developments in the language of the original user. Being very urgent when the user of a Regional language loses his spirit of love to foster and continue to maintain the existence of his mother tongue. So that in the process, the development of the Regional language dictionary in this study, converged on the study of dialectology using 200 basic vocabulary Morris Swadesh (appointed from Keraf 1984). The use of basic vocabulary is very important, because in its condition 200 basic vocabulary is always used in the community both inside and outside the country.

The development of a dictionary using 200 basic vocabulary of Morris Swadesh in this study, is that development is carried out through a filtering process which is explained in Halle's persistent generative morphology. Halle's perspective rule in the preparation of a dictionary is to register the system with morpheme data (words), then pay attention to the results of word formation and through the screening stage. The screening stage in this case is the standard work of synchronization between Indonesian as a unifying language and the Regional language which will be the target of research. So that the determination of the title of this study is the development of an Indonesian language dictionary as a form of language development and retention in the era of globalizatio.

\section{Literature}

\subsection{Dialectology Study}

The dialect comes from the Greek word dialectos which matches the accent. This word was originally used to express the linguistic system used by a community that is different from other neighboring communities but uses a system that is closely related. Meanwhile, dialectology comes from a blend of dialect words which means variations in language and logic mean science. Based on the etymology of the word, dialectology is the study of dialects 
or the study of language variations. Chambers and Trudgill (1980: 3) say that dialectology is a study of dialects or dialects. Meanwhile, Keraf (1996: 143) states that using the term geographic dialect is a branch of linguistics that specifically studies language variations based on local differences from all aspects. The language aspects in question include phonology, morphology, syntax, and lexicon and semantics.

Judging from the scope of science that underlies it, dialectology is a branch of linguistic study which arises, among others, due to the impact of the progress of comparative linguistic or diachronic linguistic studies. Dialectology is also known as dialect or geolinguistic geography. Both names arose because of the narrowing of the field of dialectology studies 'the science of language variation' has now narrowed down to a study of spatial language variations. The distribution of language variations geographically basically is closely related to comparative linguistics because both of them study the relationships contained in various languages. In subsequent developments, dialectology tends to expose the relationships between various languages by relying on the unit of space in which the various forms are realized at the time the research is conducted so that the conclusions produced can be verified (Lauder, 2001: 1). In dialectology, the final result of the analysis is diachronic refers to the prenason in the form of language mapping as a visualization so that the truth can be examined, while comparative linguistics, the end result refers to the proto language in the form of assumptions so that the truth is difficult to prove.

\subsection{Coaching And Language Retention}

Language is a living thing. As a living thing, he certainly experienced development. Development means change. This change occurs because language is the only thing that belongs to humans that has never been separated from all activities and movements of humans as creatures that are cultured and social. The attachment and interrelation of language with humans is what causes the language to become static, or in other words the language is dynamic.

Global flows also affect the use and existence of Indonesian in society. The use of language in cyberspace, the internet, facebook for example, gives many changes to the structure of the Indonesian language which some parties allegedly damaged the language itself. Based on the reasons for globalization and prestige, people are beginning to lose their sense of pride in using national languages. Not only for the small people, the language crisis was also found in state officials. Lack of intellect, he said, in every utterance it is not spiced with unnecessary foreign language interlude. This raises a new term, namely Indoglish stands for Indonesian-English for the phenomenon of language that increasingly hits Indonesian.

The shift and retention of languages are two sides of a coin (Sumarsono: 2011). This phenomenon is two phenomena that occur together. Language shifts other languages or languages that are not displaced by other languages, languages that are displaced are languages that are not able to defend themselves (Sumarsono: 2011). This condition occurs when a community (language community) chooses to use or leave the use of a language. The choice of one of these conditions occurs over a long period of time. This time span can reach more than two or three generations.

\subsection{Dictionary}

Dictionaries as a result of vocabulary codification accompanied by limits on the meaning of words and examples of their use in sentences provide guidance for their use in 
understanding words and how to use them correctly in sentences. In addition, dictionaries can help provide breadth of insight and development of reasoning power. Thus, the dictionary can be used as a means to educate someone or in a wider range as a means to educate the nation.

The bilingual dictionary uses two languages, namely the source language and the target language. Source language is a language that is an inventory object that is loaded as a dictionary input. Then, input from the source language is given an explanation of the meaning in the target language. Thus, the target language is the language used to explain the meaning of the entry from the source language as well as the example of its use.

\section{Research Methods}

The approach in this study is a qualitative approach. Qualitative approach is a new method because of its popularity not long ago, this method is also called postpositivistic because it is based on post positivity philosophy, and as an artistic method because the research process is more artistic (less patterned), and is called the interpretive method because the research data is more concerned with interpretation of the data found in the field. Quantitative research methods can be interpreted as research methods used to examine certain populations or samples, data collection uses research instruments, quantitative / statistical data analysis, with the aim of testing hypotheses that have been determined. Qualitative research methods are often called naturalistic research methods because their research is done on natural settings, also called ethnographic methods, because at first this method was used more for research in cultural anthropology.

The design in this study is In this study, the type of research that will be used is associative / relationship. In the implementation of the research method that is carried out is a survey, namely research conducted on a population by analyzing data obtained from the population itself. The intended unit of analysis is individuals, namely Regional language users (Ras Asli descendants of a language Society in the Archipelago). Data collection techniques in this study are in line with Suwartono (2014: 41), data collection is a variety of ways used to collect data, collect, retrieve, or capture research data. Get to know the interview method, observation, questionnaire, testing, archives, and documents.

\section{Results And Discussion}

The results in this study are benchmark dictionary properties which are lists of linguistic forms that have been socialized which are arranged systematically, compiled by the habits of the language of a particular language society and commented on by the author in such a way that the qualified readers understand the meaning each form is separate, and is given information about relevant facts that are related to the function of the form in the community. So that in this case, produce a dictionary reconstruction that can be considered through the following table: 


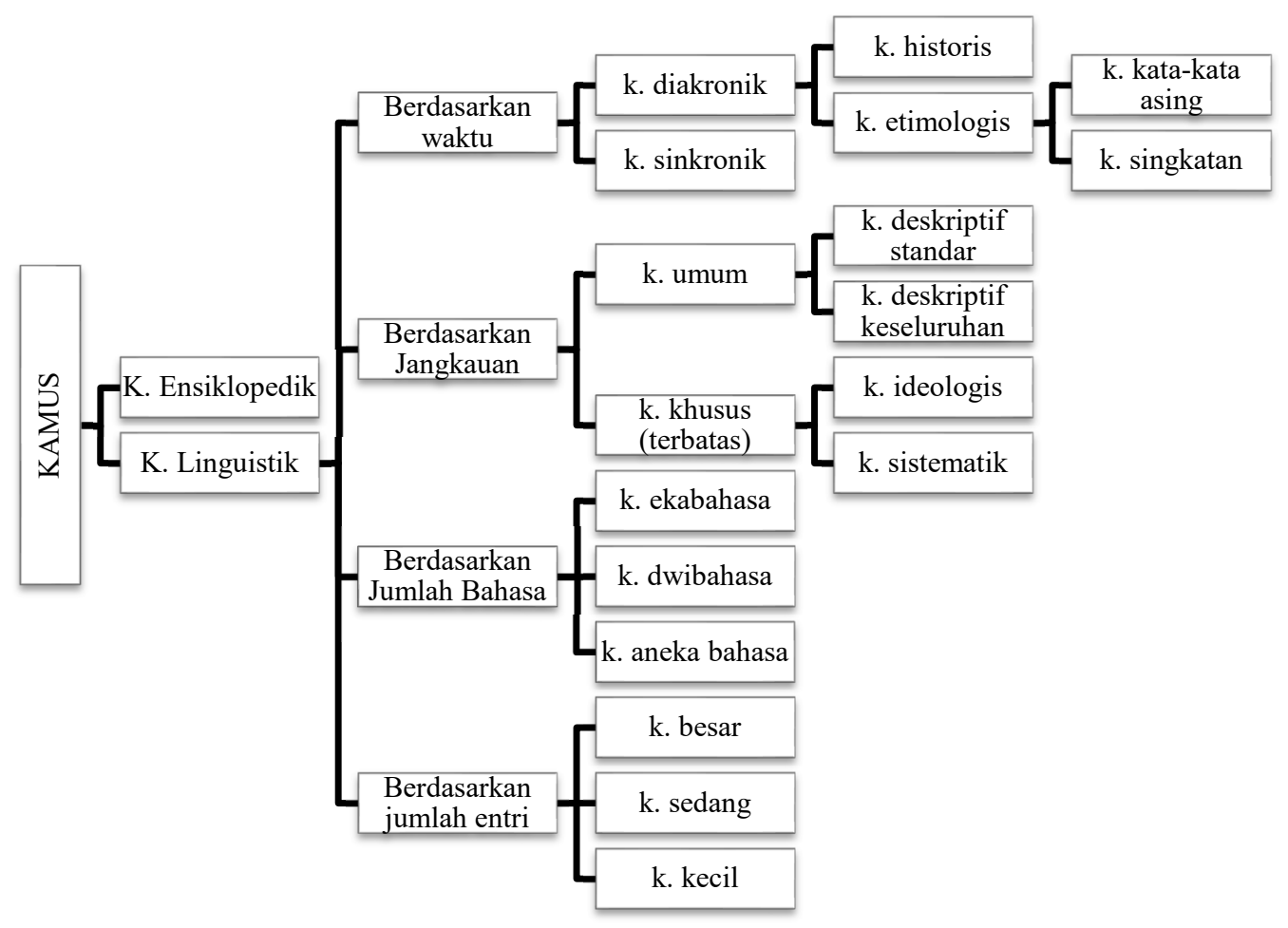

Fig 1. construction of an understanding of dictionary types

In this study, it was focused on a bilingual dictionary with a number of small entries through the following mechanism:

\section{a. Stages of Collecting Data (Heuristics)}

In the data collection stage or heuristics, all vocabulary or data contained in the data source is collected, by presenting it in cards or data slips that have been provided below, meanings, example sentences, and data source codes, based on entries, subentrices, or run on entry. Each card or data slip contains one entry or one sub-entry.

\section{b. Stages of Data Selection (Selection)}

All data that has been collected in the form of a data card or data slip is selected and selected. The really important or selected data cards are separated into one group which is the finished material for the compilation of dictionaries, while the unselected data is separated into other groups to be used if needed in checking data

c. Gradation Stages

The gradation stage is the stage of determining or selecting the main level whether or not a word that we have selected. In terms of meaning, selected words are determined or not to be included. Words are arranged sequentially based on certain fixed patterns, according to the order of entries and subentries / according to the order of derrivation of each word alphabetically and systematically according to the dictionary compilation method and in accordance with practicality. 


\section{d. Stages of Presentation (Presentation)}

This stage is the final stage of the compilation of dictionaries. In this stage, the dictionary is presented with the objectives to be achieved. Data that has been graded alphabetically and systematically clicked and presented in the form of books / dictionaries ready to use. After the presentation phase is complete, the dictionary is expected to be printed and disciplined or published to the public at large.

In this study, the application of the above mechanism is the first step in the application process in the preparation of the dictionary. The next step in the compilation of an archipelago language dictionary must pay attention to aspects of coaching and defense (the strength of language retention) to the speakers. In this study, the regional languages that were used as the object of the study were several languages of the archipelago that had stable retention in the speakers' area. The focus of taking language objects in this study focused on the eastern part of Indonesia. These languages include:
a. Ambon language
b. Ternate language
c. Buton Language
d. Papuan language

- Ayamaru language

- Maybrat Language

- Kokoda language

- Tehit-Sorong Selatan Language

The taking of respondents in the mechanism of composing the language dictionary of the archipelago must be native speakers of the language. Through observation techniques, 7 respondents from native languages of the archipelago were obtained who still had retention of the language. Through the questionnaire technique following the original data after conducting field observations as one of the work stages of data collection (Heuristics).

Table 1. Questionnaire 1: Speakers of Ambon Language

\begin{tabular}{|l|l|c|c|c|c|c|}
\hline No & \multicolumn{1}{|c|}{ Type } & Always & Often & Sometimes & Rarely & Nothing \\
\hline 1 & Family & $\sqrt{ }$ & & & & \\
\hline 2 & Neighbor & & $\sqrt{ }$ & & & \\
\hline 3 & Office colleagues & & $\sqrt{ }$ & & & \\
\hline 4 & Officialls & & & $\sqrt{ }$ & & \\
\hline 5 & General & & & $\sqrt{ }$ & & \\
\hline
\end{tabular}

Table 2. Questionnaire 2: Speakers of Ternate Language

\begin{tabular}{|l|l|c|c|c|c|c|}
\hline No & \multicolumn{1}{|c|}{ Type } & Always & Often & Sometimes & Rarely & Nothing \\
\hline 1 & Family & $\sqrt{ }$ & & & & \\
\hline 2 & Neighbor & & $\sqrt{ }$ & & & \\
\hline 3 & Office colleagues & & & $\sqrt{ }$ & & \\
\hline 4 & Officialls & & & $\sqrt{ }$ & & \\
\hline 5 & General & & & & $\sqrt{ }$ & \\
\hline
\end{tabular}


Table 3. Questionnaire 3: Speakers of Buton Language

\begin{tabular}{|l|l|c|c|c|c|c|}
\hline No & \multicolumn{1}{|c|}{ Type } & Always & Often & Sometimes & Rarely & Nothing \\
\hline 1 & Family & $\sqrt{ }$ & & & & \\
\hline 2 & Neighbor & & & & $\sqrt{ }$ & \\
\hline 3 & Office colleagues & & & & & $\sqrt{ }$ \\
\hline 4 & Officialls & & & $\sqrt{ }$ & & \\
\hline 5 & General & & & $\sqrt{ }$ & & \\
\hline
\end{tabular}

Table 4.Questionnaire 4: Speakers of Ayamaru Language

\begin{tabular}{|l|l|c|c|c|c|c|}
\hline No & \multicolumn{1}{|c|}{ Type } & Always & Often & Sometimes & Rarely & Nothing \\
\hline 1 & Family & $\sqrt{ }$ & & & & \\
\hline 2 & Neighbor & & $\sqrt{ }$ & & & \\
\hline 3 & Office colleagues & & $\sqrt{ }$ & & & \\
\hline 4 & Officialls & & & $\sqrt{ }$ & & \\
\hline 5 & General & & & & & $\sqrt{ }$ \\
\hline
\end{tabular}

Table 5. Questionnaire 5: Speakers of Maybrat Language

\begin{tabular}{|l|l|c|c|c|c|c|}
\hline No & \multicolumn{1}{|c|}{ Type } & Always & Often & Sometimes & Rarely & Nothing \\
\hline 1 & Family & $\sqrt{ }$ & & & & \\
\hline 2 & Neighbor & & $\sqrt{ }$ & & & \\
\hline 3 & Office colleagues & & & $\sqrt{ }$ & & \\
\hline 4 & Officialls & & & $\sqrt{ }$ & & \\
\hline 5 & General & & & & & $\sqrt{ }$ \\
\hline
\end{tabular}

Table 6. Questionnaire 6: Speakers of Kokoda Language

\begin{tabular}{|l|l|c|c|c|c|c|}
\hline No & \multicolumn{1}{|c|}{ Type } & Always & Often & Sometimes & Rarely & Nothing \\
\hline 1 & Family & $\sqrt{ }$ & & & & \\
\hline 2 & Neighbor & & & $\sqrt{ }$ & & \\
\hline 3 & Office colleagues & & & & & $\sqrt{ }$ \\
\hline 4 & Officialls & & & & $\sqrt{ }$ & \\
\hline 5 & General & & & & \\
\hline
\end{tabular}

Table 7.Questionnaire 7: Speakers of Tehit Language

\begin{tabular}{|l|l|c|c|c|c|c|}
\hline No & \multicolumn{1}{|c|}{ Type } & Always & Often & Sometimes & Rarely & Nothing \\
\hline 1 & Family & $\sqrt{ }$ & & & & \\
\hline 2 & Neighbor & & $\sqrt{ }$ & & & \\
\hline 3 & Office colleagues & & & & $\sqrt{ }$ & \\
\hline 4 & Officialls & & & $\sqrt{ }$ & & \\
\hline 5 & General & & & $\sqrt{ }$ & & \\
\hline
\end{tabular}

The questionnaire diagram in this study can be considered below 


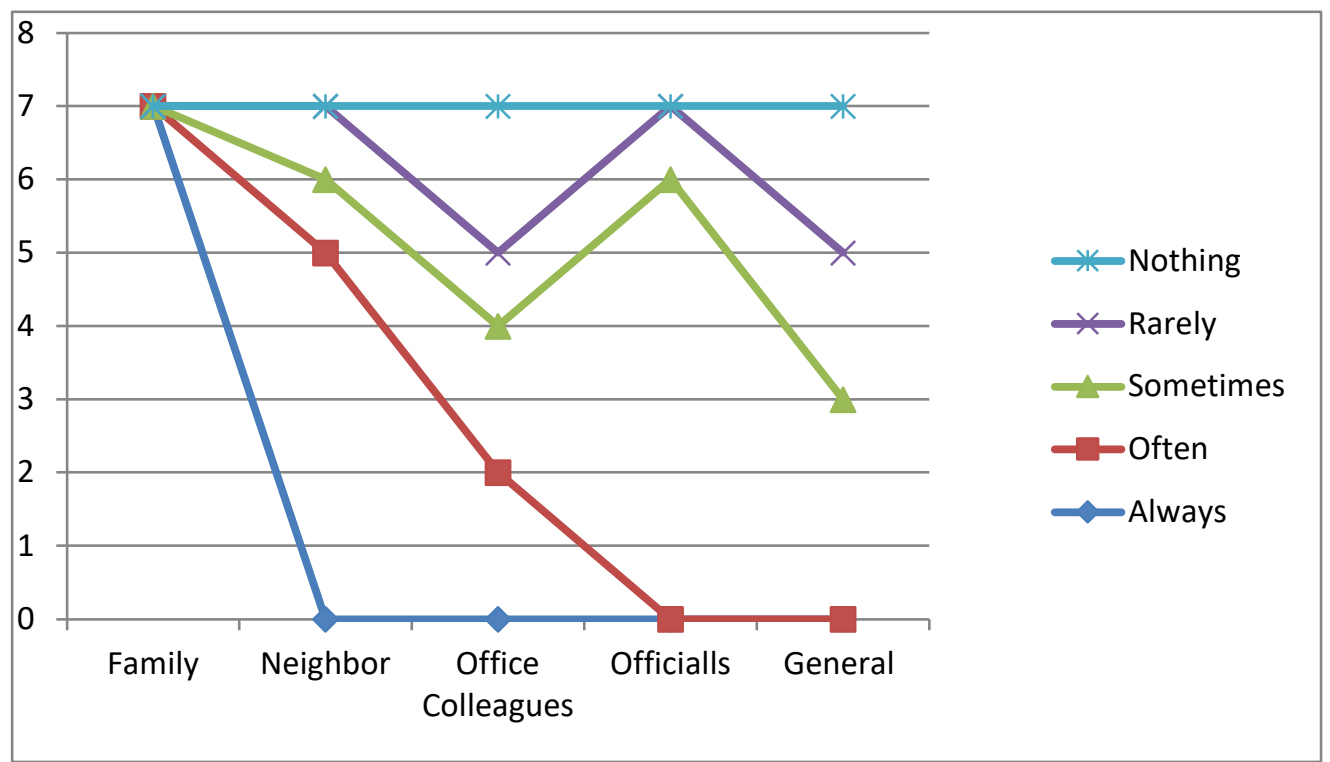

Fig 2. Questionnaire diagram

From the results of the Fig 2, it can be explained that the level of use of the language of the Mother (Regional Language) by the speaker has the highest retention in the family sector, all respondents said that in the family environment they always use Mother tongue. Whereas in the other environment, as stated in the diagram that (the neighboring environment, coworkers, officials, and the public) still has a moderate level to the bottom or it can be said that the level of use of the mother language is not too dominant based on the situation in heterogeneous conditions one environment. This, which makes the benchmark that the preparation of bilingual bilingual regions of the archipelago was developed.

In the next step, namely the stage of selecting the next mechanism, the application of Morris Swadesh's basic vocabulary list. At this stage, the selected vocabulary is 15 subvocabulary which will then be filtered into the Regional language. 15 of these include:

a. Vocabulary of the body part

b. Pronouns, greetings, and designations

c. Kinship term

d. Village life and community

e. House and its parts

f. Equipment and equipment

g. Food and Drink

h. Plants, parts, fruits, and processed products

i. Animals and their parts

j. Time, season, natural conditions, natural objects, and directions

k. Motion and work

1. Temperament, nature and color

m. Disease

n. Clothing and jewelry

o. Numbers and sizes 
In the next stage, the mechanism carried out is to enter the gradas stage. In this stage, dictionary entries are arranged alphabetically in order (A-Z). The following is an excerpt of the image resulting from the development of a language dictionary in Ambone

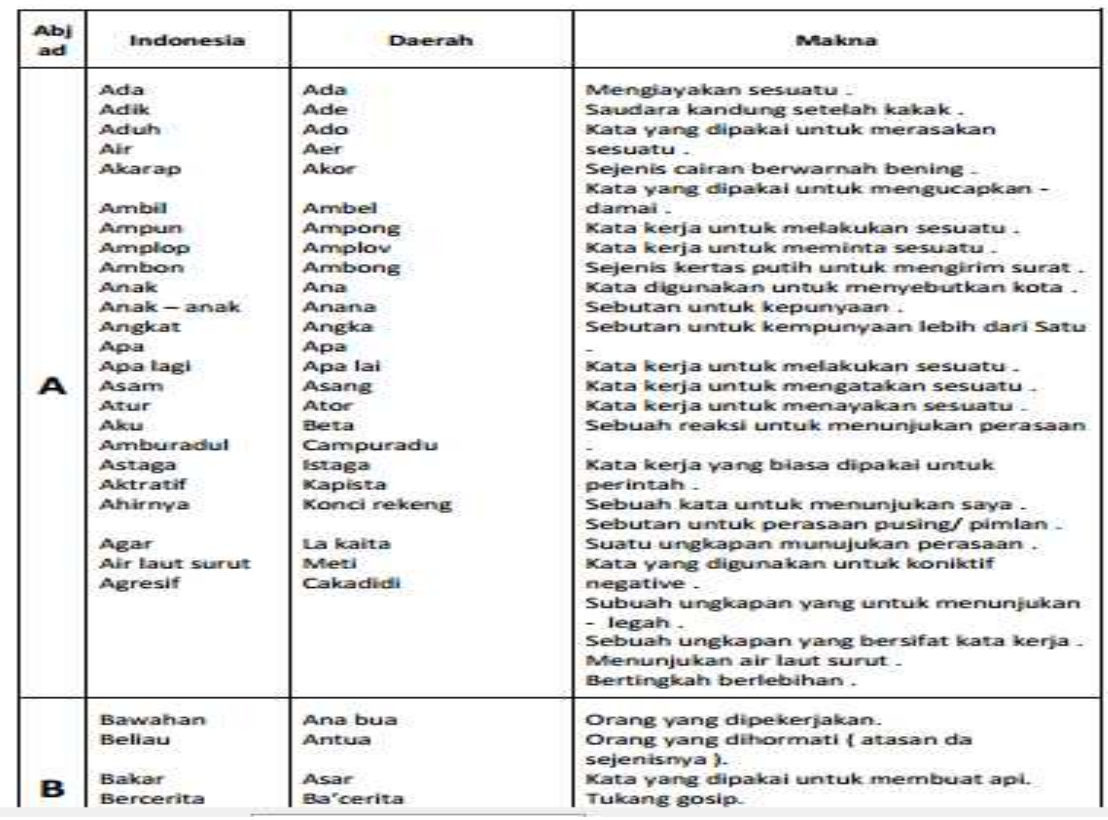

Fig 3. Ambone Dictionary

In this phase of the phase, all language data of the target area have been collected systematically and in accordance with alphabetical and lexical meanings in accordance with KBBI (Indonesian Dictionary). Furthermore, the dictionary entry is included in the last mechanism, namely the presentation of data that has been graded alphabetically and systematically diik and presented in the form of books / dictionaries ready to use.

\section{Conclution}

The conclusions of this study include the construction of a mechanism for the compilation of bilingual dictionaries of the archipelago through the application of dialectological studies that practice the basic vocabulary principle of Morris Swadesh. The conclusion is a bilingual dictionary with a number of small entries through four stages, including:

- $\quad$ Stages of collecting data (Heuristics)

- $\quad$ Stages of data selection (Selection)

- $\quad$ gradation stages

- $\quad$ Stages of presentation (Presentation)

In this study, it was found data that the level of use of the language of the Mother (Regional Language) by the speakers had the highest retention in the family sector, all 
respondents said that in the family environment they always use Mother tongue. Whereas in the other environment, as stated in the diagram that (the neighboring environment, co-workers, officials, and the public) still has a moderate level to the bottom or it can be said that the level of use of the mother language is not too dominant based on the situation in heterogeneous conditions one environment. This, which makes the benchmark that the preparation of bilingual bilingual regions of the archipelago was developed. all the language data of the target area have been collected systematically and in accordance with the alphabet and accompanied by lexical meanings in accordance with KBBI (Indonesian Dictionary). Furthermore, the dictionary entry is included in the last mechanism, namely the presentation of data that has been graded alphabetically and systematically and presented in the form of books / dictionaries ready to use.

\section{Reference}

[1] Chaer. Abdul. 2007. Linguistik Umum. Jakarta: Rineka Cipta.

[2] Chaer. Abdul. 2007. Kajian Bahasa: Struktur Internal, Pemakaian, dan Pemelajaran. Jakarta: Rineka Cipta.

[3] Sumarsono. 2011. Metode Riset Sumber Daya Manusia. Jakarta: PT. Graha Ilmu Suwartono. 2014. Dasar-Dasar Metodologi Penelitian. Jogjakarta: Andi Offset Press. 